\title{
Fathead minnows learn to recognize predator odour when exposed to concentrations of artificial alarm pheromone below their behavioural- response threshold
}

\author{
Grant E. Brown, James C. Adrian, Jr., Todd Patton, and Douglas P. Chivers
}

\begin{abstract}
Hypoxanthine-3- $N$-oxide (H3NO) has been identified as the putative alarm pheromone of ostariophysan fishes. Previously we demonstrated a population-specific minimum behavioural-response threshold in fathead minnows (Pimephales promelas) to a $\mathrm{H} 3 \mathrm{NO}$ concentration of approximately $0.4 \mathrm{nM}$. Minnows may, however, perceive low concentrations of $\mathrm{H} 3 \mathrm{NO}$ as a predation threat, even though they do not exhibit an overt behavioural response. We conducted a series of laboratory trials to test the hypothesis that minnows can detect the alarm pheromone at concentrations below the minimum behavioural-response threshold. We exposed predator-naïve fathead minnows to $\mathrm{H} 3 \mathrm{NO}$ at concentrations ranging from 0.4 to $0.05 \mathrm{nM}$ paired with the odour of a novel predator (yellow perch, Perca flavescens) or distilled water paired with perch odour. We observed significant increases in antipredator behaviour (increased shoal cohesion, movement towards the substrate, a reduction in feeding, and an increase in the occurrence of dashing and freezing behaviour) in shoals of minnows exposed to a combined cue of $0.4 \mathrm{nM} \mathrm{H} 3 \mathrm{NO}$ and perch odour (compared with a distilled-water control), but not by shoals exposed to lower concentrations of H3NO paired with perch odour or those exposed to distilled water paired with perch odour. When exposed to perch odour alone 4 days later, minnows initially conditioned to $\mathrm{H} 3 \mathrm{NO}$ at concentrations of $0.4-0.1 \mathrm{nM}$ exhibited significant increases in antipredator behaviour. These data demonstrate that minnows attend to the alarm pheromone at concentrations below the minimum behavioural-response threshold and are able to acquire the ability to recognize a novel predator even though they do not exhibit an overt behavioural response.
\end{abstract}

Résumé : L'oxyde 3-N d'hypoxanthine (H3NO) est, croit-on, la phéromone d'alerte des poissons ostariophyses. Nous avons déjà démontré l'existence d'un seuil minimum de réaction comportementale spécifique à la population chez le Tête-de-boule (Pimephales promelas) à l'H3NO d'environ 0,4 nM. Les Têtes de-boule peuvent cependant percevoir de l'H3NO en faibles concentrations comme la menace d'un prédateur, même s'ils n'ont pas de réaction comportementale marquée. Nous avons procédé à une série d'essais en laboratoire pour vérifier l'hypothèse selon laquelle les poissons peuvent détecter la phéromone d'alerte sous le seuil minimum de réaction comportementale. Nous avons exposé des Têtes-de-boule, qui ne l'avaient jamais été auparavant, à de l'H3NO en concentrations de 0,4 à 0,05 nM en présence de l'odeur d'un prédateur qui leur était inconnu (la perchaude, Perca flavescens) ou mis dans de l'eau distillée en présence d'odeur de perchaude. Nous avons observé des augmentations significatives du comportement anti-prédateurs (plus de cohésion dans les bancs, déplacements vers le substrat, réduction de l'alimentation, augmentation des mouvements impétueux et des arrêts brusques) dans les bancs de poissons exposés à la combinaison d'H3NO $0,4 \mathrm{nM}$ et d'odeur de perchaude (l'eau ordinaire servait de témoin), mais pas dans les bancs exposés aux concentrations plus faibles d'H3NO avec odeur de perchaude, ni dans les bancs mis en eau distillée avec odeur de perchaude. Exposés à l'odeur de perchaude seule 4 jours plus tard, les poissons acclimatés au départ à des concentrations d'H3NO de 0,4 à 0,1 nM ont adopté un comportement anti-prédateurs significativement plus marqué. Ces données démontrent que les Têtes-de-boule peuvent percevoir la phéromone d'alerte en concentrations inférieures au seuil minimum de réaction comportementale et sont capables de reconnaître un prédateur nouveau, même s'ils ne montrent pas de réaction comportementale manifeste.

[Traduit par la Rédaction]

Received May 16, 2001. Accepted October 9, 2001. Published on the NRC Research Press Web site at http://cjz.nrc.ca on January 4, 2002.

G.E. Brown ${ }^{\mathbf{1}, 2}$ and T. Patton. Department of Biological Sciences, Science and Engineering Center, Union College, Schenectady, NY 12308, U.S.A.

J.C. Adrian, Jr. Department of Chemistry, Science and Engineering Center, Union College, Schenectady, NY 12308, U.S.A.

D.P. Chivers. Department of Biology, University of Saskatchewan, 112 Science Place, Saskatoon, SK S7N 5E2, Canada.

${ }^{1}$ Corresponding author (e-mail: gbrown@alcor.concordia.ca).

${ }^{2}$ Present address: Department of Biology, Concordia University, 1455 de Maisonneuve West, Montreal, QC H3G 1M8, Canada. 


\section{Introduction}

Many ostariophysan fishes possess specialized epidermal club cells that, when mechanically damaged (as would occur during a predation event), release a chemical alarm signal or alarm pheromone into the water column (Smith 1992; Chivers and Smith 1998). When detected by nearby conspecifics and some sympatric heterospecifics, this chemical signal elicits dramatic short-term increases in species-specific antipredator behaviours (alarm response; Smith 1992, 1999; Chivers and Smith 1998; Mirza and Chivers 2001). Although it is the subject of controversy (Magurran et al. 1996; Smith 1997; Brown and Godin 1999a), there exists a wealth of evidence for the antipredator function of alarm pheromones in ostariophysan fishes, for both signal senders and receivers (Chivers and Smith 1998; Brown and Godin 1999a, 1999b; Brown et al. 1999; Smith 1999).

Pfeiffer et al. (1985) previously argued that hypoxanthine$3-N$-oxide (H3NO), which is characterized by a purine skeleton and a nitrogen oxide functional group at the 3 position (Fig. 1), is the single active component within the ostariophysan alarm pheromone system. Recently, however, Brown et al. (2000) and Brown et al. (2001a) have shown that the nitrogen oxide functional group acts as the chief molecular trigger and that other, structurally diverse molecules with this functional group may also act as an alarm signal.

Two cyprinid species (fathead minnow, Pimephales promelas, and finescale dace, Phoxinus neogaeus) and two characin species (glowlight tetra, Hemigrammus erythrozonus, and neon tetra, Paracheirodon innesi) exhibited an increase in antipredator responses of similar intensity to $\mathrm{H} 3 \mathrm{NO}$ and natural skin extracts and a significant but weaker response to the structurally dissimilar pyridine- $N$-oxide (Brown et al. 2000, 2001a). In addition, G.E. Brown, J.C. Adrian and J.M. Tower (unpublished data) have shown that replacing the double-bonded oxygen in the 1 position of $\mathrm{H} 3 \mathrm{NO}$ (Fig. 1) with progressively larger alkoxy functional groups appears to have no effect on the ability of $\mathrm{H} 3 \mathrm{NO}$ to elicit significant alarm responses, and that trimethylamine- $N$-oxide and 4methylmorpholine- $N$-oxide (non-aromatic compounds) also elicit significant increases in antipredator behaviour.

Recently, Brown et al. (2001b) have shown that fathead minnows from a low predation risk population show consistent behavioural responses (an increase in antipredator behaviour) to $\mathrm{H} 3 \mathrm{NO}$ at concentrations as low as $0.4 \mathrm{nM}$. No significant antipredator response was observed at concentrations below this threshold. However, unpublished reports by A. Mathis and R.J.F. Smith suggest that this minimum behavioural-response threshold may be population-specific, with minnows from high predation risk populations exhibiting significant increases in antipredator behaviour at concentrations at least one order of magnitude lower than those reported by Brown et al. (2001b).

Selection pressure resulting from population-specific predation may act on the minnow's ability to detect and respond to conspecific alarm pheromones in one of two ways. Initially, predation pressure could act on the minimum behaviouralresponse threshold itself, with minnows from high predation risk populations responding to lower relative concentrations of the alarm pheromone ("response-threshold mechanism"). Secondly, predation pressure could act on the ability of indi-
Fig. 1. Hypoxanthine-3- $N$-oxide, with the standard purine numbering scheme.

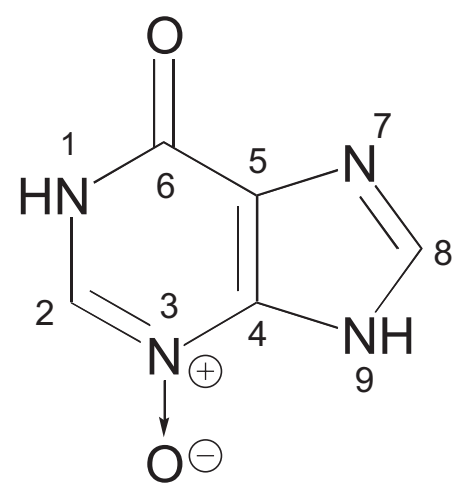

viduals within a population to detect alarm pheromones at varying concentrations ("stimulus-detection mechanism"). In the first case, individuals from different populations would be able to detect conspecific alarm pheromones and "choose" to respond or not respond to the chemical signal depending upon population-specific predation pressure. In the second case, selection would act directly on the ability of individuals to detect the alarm pheromone, i.e., individuals from high predation risk populations might be expected to have a greater density of olfactory receptors.

Fathead minnows must learn to recognize the chemical and (or) visual cues of novel predators (Chivers and Smith 1994a, 1994b; Brown et al. 1997). Minnows reared under laboratory conditions or collected from populations devoid of northern pike (Esox lucius) do not recognize either the visual or the chemical cues of this common predator (Mathis et al. 1993; Chivers and Smith 1994b). However, they rapidly learn to recognize these cues as a predation threat when either is paired with conspecfic skin extract (Chivers and Smith 1994a, 1994b, 1995; Brown et al. 1997). Brown and Smith (1996) have demonstrated that this predator-induced recognition learning (Suboski 1990, 1992a, 1992b) can occur in the absence of an overt behavioural response to the presence of conspecific alarm pheromone. Minnows that had been food-deprived for 24-48 h failed to exhibit a significant increase in antipredator behaviour when exposed to the paired stimulus of conspecific skin extract and predator odour. However, when fed to satiation and retested several days later with predator odour alone, minnows exhibited significant antipredator responses (Brown and Smith 1996). This demonstrates that even though food-deprived minnows were not exhibiting an overt behavioural response (as a result of a threat-sensitive foraging trade-off; Brown and Smith 1996; Smith 1999), they were attending to the presence of the alarm pheromone and using this information to acquire the ability to recognize a novel predator.

It is not known whether minnows exposed to subthreshold concentrations of $\mathrm{H} 3 \mathrm{NO}$ do not respond because they fail to detect the alarm signal (stimulus-detection mechanism) or "choose" not to respond because of the relatively low concentration (response-threshold mechanism). By pairing varying concentrations of $\mathrm{H} 3 \mathrm{NO}$ with the chemical cues of a novel predator we can directly address this question. 


\section{Methods}

\section{Fish collection and stimulus preparation}

Fathead minnows were collected from an outlet pond at the State University of New York, Cobbleskill (SUNY Cobbleskill), New York. This population is exposed to relatively low predation pressure, as the only fish species present are the fathead minnow and common sucker (Catostomus commersoni). Minnows were held in 60-L aquaria filled with continuously filtered, dechlorinated tap water $\left(\mathrm{pH} 8.0,18^{\circ} \mathrm{C}\right)$ on a $12 \mathrm{~h}$ light (L) : $12 \mathrm{~h}$ dark (D) cycle and were fed ad libitum twice daily (at 07:30 and 13:30) with commercial flake food. Length at testing was $4.58 \pm 0.42 \mathrm{~cm}$ (mean $\pm \mathrm{SE}$ ). Yellow perch (Perca flavescens) were collected from Ballston Lake, New York, and held in 60-L aquaria under the same conditions as the minnows. Prior to stimulus collection, perch were maintained on a diet of brine shrimp (Artemia francisca) and fathead minnows.

Prey animals often exhibit antipredator responses to chemical cues of predators fed conspecifics of the prey, but not to those of predators fed another diet (Chivers and Mirza 2001). Consequently, we altered the diet of our predatory perch prior to stimulus collection. We fed two yellow perch (15.5 and $16.8 \mathrm{~cm}$ standard length) approximately $4.0 \mathrm{~mL}$ (measured by volumetric displacement in water) of green swordtails (Xiphophorus helleri) daily for 5 consecutive days. We used swordtails as a control diet, since they lack the ostariophysan alarm pheromone and are allopatric from minnows. One hour after the final feeding, we transferred each perch to a 5-L stimulus-collection tank (filled with $3 \mathrm{~L}$ of dechlorinated tap water). The stimulus-collection tanks were aerated but not filtered. The perch remained in the stimulus-collection tanks for $48 \mathrm{~h}$, at which time they were removed and returned to their holding tanks. We pooled the water from the two tanks and filtered it through filter floss to remove any particulate matter. Water containing perch odour was frozen at $-20^{\circ} \mathrm{C}$ in $50-\mathrm{mL}$ aliquots until required.

H3NO was synthesized according to Brown et al. (2000). Stock solutions of the experimental stimuli were prepared by dissolving $\mathrm{H} 3 \mathrm{NO}$ in glass-distilled water to concentrations of $2.9,1.5,0.7$, and $0.4 \mu \mathrm{M}$. Stock solutions of $\mathrm{H} 3 \mathrm{NO}$ were frozen at $-20^{\circ} \mathrm{C}$ in $50-\mathrm{mL}$ aliquots until required.

\section{Conditioning trials}

Test tanks consisted of 37-L aquaria filled with $35 \mathrm{~L}$ of dechlorinated tap water and equipped with a gravel substrate and a single airstone mounted along the back wall. A 3-m length of airline tubing was attached to the airstone so that chemical stimuli could be injected into the tank from behind a black plastic viewing curtain without disturbing the test fish. The test tanks were divided into three equal horizontal sections with markings in the exterior of the tank to facilitate recording of vertical area use (see below).

We placed shoals of four fathead minnows (matched for size) in the test tanks and allowed a 48-h acclimation period. Each shoal was tested twice, once in the morning with distilled water as the stimulus and once in the afternoon with test stimuli. Each observation consisted of paired control and experimental observations. Control and experimental observations consisted of a 10-min prestimulusinjection and a 10-min poststimulus-injection observation period. During both the pre- and post-stimulus observation periods, we recorded area use and shoaling index every $15 \mathrm{~s}$. Vertical area use was recorded as the position of each fish within the test tank $(1=$ bottom third of the test tank, $3=$ top third of the test tank), yielding scores ranging from 4 (all fish near the substrate) to 12 (all fish near the surface). Shoaling-index scores (modified from Mathis and Smith 1993) ranged from 1 (no fish within one body length of another) to 4 (all fish within one body length of each other). In addition, we recorded the occurrence of dashing, freezing, and active-foraging behaviours. Dashing was defined as a sudden burst of apparently disoriented swimming, freezing as the cessation of movement, with the minnow settling to the substrate and remaining motionless for at least $30 \mathrm{~s}$, and foraging as active searching or ingestion of food from the substrate, with a body position at least $45^{\circ}$ to the substrate. Movement towards the substrate, a decrease in foraging, and an increase in shoaling as well as the presence of dashing and freezing behaviour are indicative of an increase in antipredator response in fathead minnows (Chivers and Smith 1998; Brown et al. 2000, 2001b).

Following the prestimulus observation period we withdrew and discarded $60 \mathrm{~mL}$ of tank water through the stimulus-injection tube. An additional $60 \mathrm{~mL}$ was then withdrawn and retained. For distilled-water (control) trials, we injected $5 \mathrm{~mL}$ of distilled water and slowly (about $60 \mathrm{~s}$ ) flushed it into the tank with the retained tank water. For trials utilizing test stimuli, we injected $5 \mathrm{~mL}$ of $\mathrm{H} 3 \mathrm{NO}$ (at each of the four concentrations described above) paired with $10 \mathrm{~mL}$ of perch odour (experimental treatments) or $5 \mathrm{~mL}$ of distilled water paired with $10 \mathrm{~mL}$ of perch odour (control treatment). Thus, the final dilution of $\mathrm{H} 3 \mathrm{NO}$ in the test tanks was $0.4,0.2,0.1$, or $0.05 \mathrm{nM}$ (sensu Brown et al. 2001b). Our control treatment consisting of distilled water paired with perch odour allowed us to ensure that the population of minnows tested was indeed naïve to perch odour.

Distilled-water trials were run between 08:00 and 11:00 daily, and trials utilizing test stimuli (perch odour paired with $\mathrm{H} 3 \mathrm{NO}$ or distilled water) were run between 13:00 and 16:00 daily. The $12 \mathrm{~h} \mathrm{~L}$ : $12 \mathrm{~h}$ D cycle began at 06:00, so the distilled-water trials began at least $2 \mathrm{~h}$ after the lights came on. Distilled-water trials were conducted before trials utilizing test stimuli, as any response to the test stimuli may have masked a response to the control stimuli (Lawrence and Smith 1989; Hazlett 1997). During the trials with perch odour paired with $\mathrm{H} 3 \mathrm{NO}$ or distilled water, the observer was unaware of which stimulus was being tested, hence controlling for any observer bias.

For area use and shoaling-index scores we calculated the difference between the pre- and post-stimulus observation periods and compared the distilled-water control versus experimental values using a Wilcoxon's signed-ranks test (Siegel and Castellan 1988). We compared the frequency of occurrence of dashing, freezing, and foraging behaviours between the distilled-water and test-stimulus trials using a McNemar change test (Siegel and Castellan 1988).

\section{Acquired predator recognition trials}

To determine if the minnows had acquired the ability to recognize a novel predator cue, we exposed conditioned minnows to perch odour alone 4 days after the conditioning trials. The experimental protocol and statistical analysis were as described above, with the exception that the test stimulus consisted of $10 \mathrm{~mL}$ of perch odour alone.

\section{Results}

\section{Conditioning trials}

We found a significant decrease in area use by minnows exposed to $\mathrm{H} 3 \mathrm{NO}$ at a concentration of $0.4 \mathrm{nM}$ (Fig. 2A, Table 1). No significant change in area use was seen for minnows exposed to $\mathrm{H} 3 \mathrm{NO}$ at lower concentrations or those exposed to perch odour paired with distilled water (Fig. 2A, Table 1). Likewise, we found a significant increase in shoaling index only in minnows exposed to $\mathrm{H} 3 \mathrm{NO}$ at a concentration of $0.4 \mathrm{nM}$, but not to lower concentrations or perch odour paired with distilled water (Fig. 2B, Table 1).

We observed a similar trend in the frequency of occurrence of dashing, freezing, and active-foraging behaviours (Table 2). Minnows exposed to $0.4 \mathrm{nM}$ H3NO exhibited significant increases in dashing and freezing behaviour and significant 
Fig. 2. Changes (mean \pm SE) in area use (A) and shoaling index (B) by shoals of fathead minnows (Pimephales promelas) exposed to a paired stimulus of hypoxanthine-3- $N$-oxide at concentrations of $0.4,0.2,0.1$, and $0.05 \mathrm{nM}$ and perch odour or distilled water and perch odour (PO). Open bars represent distilled-water trials and shaded bars represent paired perch odour and H3NO (experimental treatments) or perch odour and distilled water (control treatments) trials. An asterisk denotes a significant difference at $P<0.05$, based on Wilcoxon's signed-ranks tests (see the text for details; $N=10$ per treatment).
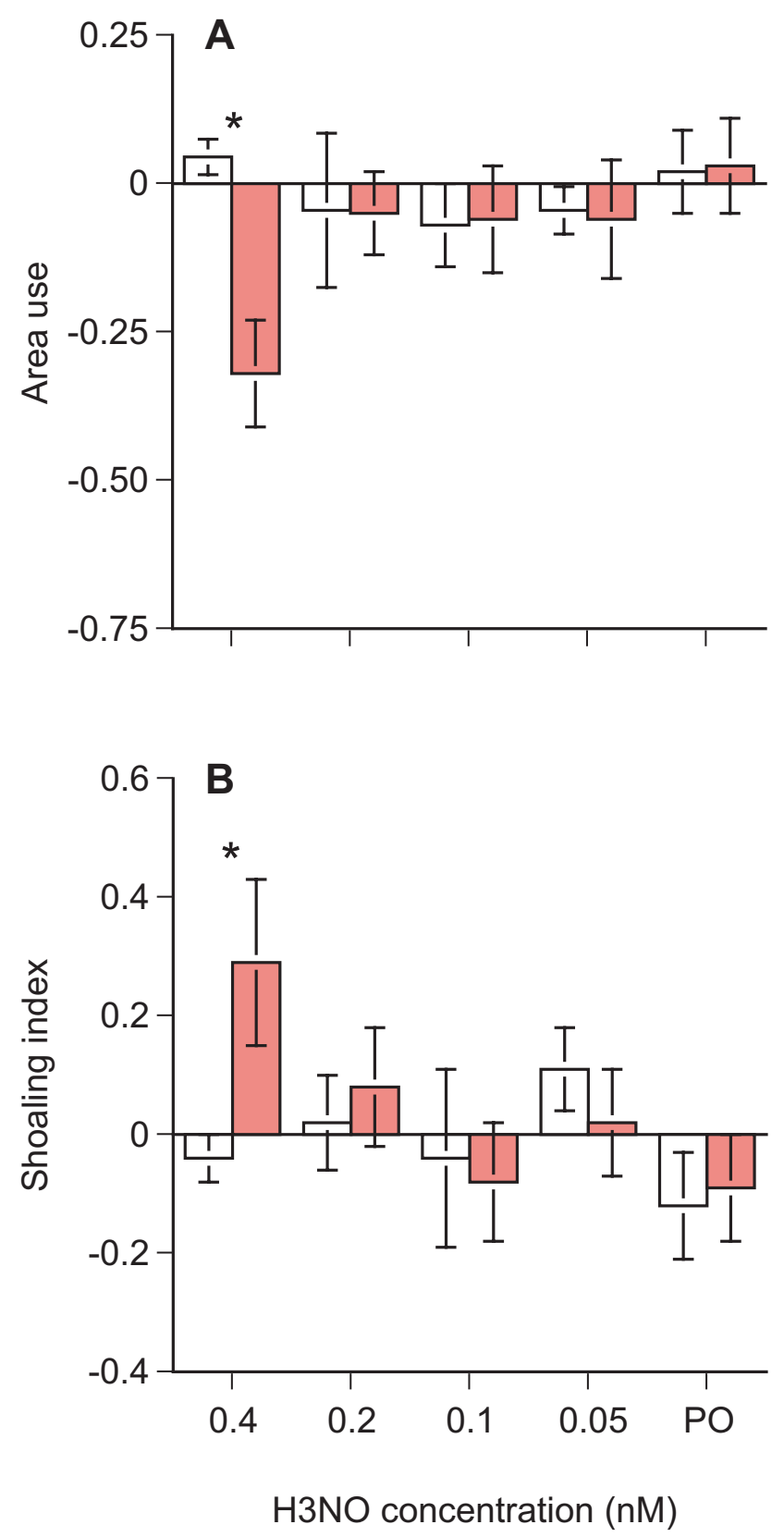

decreases in active foraging (Table 2). We also observed a significant increase in dashing behaviour by minnows exposed to $0.2 \mathrm{nM} \mathrm{H} 3 \mathrm{NO}$.

\section{Acquired predator recognition trials}

When exposed to perch odour alone, minnows originally conditioned with the predator cue paired with $\mathrm{H} 3 \mathrm{NO}$ at
Fig. 3. Changes (mean $\pm \mathrm{SE}$ ) in area use (A) and shoaling index (B) by shoals of fathead minnows exposed to perch odour alone 4 days following the conditioning trials. Open bars represent distilled-water trials and shaded bars represent changes in response by minnows initially exposed to paired perch odour and H3NO (experimental treatments) or perch odour and distilled water (control treatments). An asterisk denotes a significant difference at $P<0.05$, based on Wilcoxon's signed-ranks tests (see the text for details; $N=10$ per treatment).
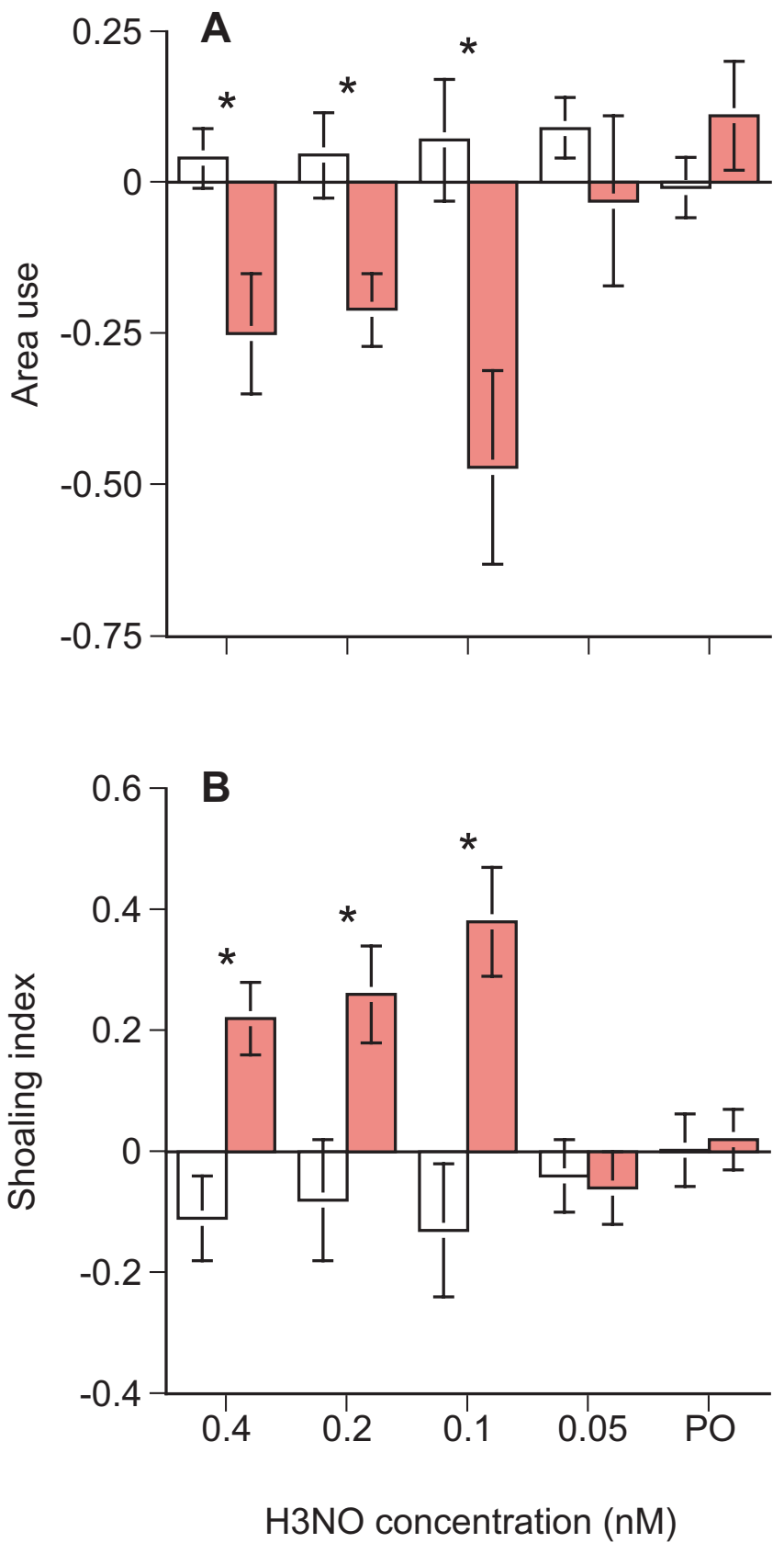

concentrations of $0.4-0.1 \mathrm{nM}$ significantly decreased area use (Fig. 3A, Table 1) and significantly increased shoaling index (Fig. 3B, Table 1). Those initially exposed to distilled water or $0.05 \mathrm{nM} \mathrm{H} 3 \mathrm{NO}$ did not significantly alter area use or shoaling index when exposed to perch odour alone (Fig. 3, Table 1). Likewise, minnows conditioned to perch odour paired with $0.4,0.2$, and $0.1 \mathrm{nM} \mathrm{H} 3 \mathrm{NO}$ significantly 
Table 1. Comparisons of area use and shoaling-index scores for fathead minnows (Pimephales promelas) exposed to varying concentrations of hypoxanthine-3- $N$-oxide or a distilled-water control in conditioning trials (H3NO or distilled water + perch odour) and acquired-predator-recognition (APR) trials (perch odour alone).

\begin{tabular}{|c|c|c|c|c|c|c|c|c|}
\hline \multirow[b]{3}{*}{ Treatment (nM) } & \multicolumn{4}{|c|}{ Area use } & \multicolumn{4}{|c|}{ Shoaling index } \\
\hline & \multicolumn{2}{|c|}{ Conditioning trial } & \multicolumn{2}{|c|}{ APR trials } & \multicolumn{2}{|c|}{ Conditioning trial } & \multicolumn{2}{|c|}{ APR trials } \\
\hline & $Z$ & $P$ & $Z$ & $P$ & $Z$ & $P$ & $Z$ & $P$ \\
\hline 0.4 & -2.80 & $<0.005$ & -2.09 & $<0.04$ & -1.99 & $<0.05$ & -2.80 & $<0.005$ \\
\hline 0.2 & -0.26 & ns & -1.99 & $<0.05$ & -0.46 & ns & -2.29 & $<0.03$ \\
\hline 0.1 & -0.41 & ns & -2.70 & $<0.01$ & -0.05 & ns & -2.70 & $<0.01$ \\
\hline 0.05 & -0.36 & ns & -0.71 & $\mathrm{~ns}$ & -0.56 & $\mathrm{~ns}$ & -0.05 & ns \\
\hline PO & -0.01 & ns & -0.96 & ns & -0.97 & ns & -0.30 & ns \\
\hline
\end{tabular}

Note: Probabilities are based on Wilcoxon's signed-ranks tests (Siegel and Castellan 1988); ns, not significant; see the text for details.

Table 2. Dashing, freezing, and active-foraging behaviour in response to perch odour paired with hypoxanthine-3- $N$-oxide at varying concentrations or distilled water (experimental) or distilled-water control (distilled-water) trials during conditioning trials.

\begin{tabular}{|c|c|c|c|c|c|c|c|c|c|c|}
\hline \multirow[b]{2}{*}{ Treatment (nM) } & \multirow[b]{2}{*}{ Stimulus } & \multicolumn{3}{|c|}{ Dashing } & \multicolumn{3}{|c|}{ Freezing } & \multicolumn{3}{|c|}{ Foraging } \\
\hline & & Yes & No & $P$ & Yes & No & $P$ & Yes & No & $P$ \\
\hline \multirow[t]{2}{*}{0.4} & Distilled-water & 0 & 10 & $<0.001$ & 0 & 10 & $<0.001$ & 10 & 0 & 0.003 \\
\hline & Experimental & 10 & 0 & & 8 & 2 & & 3 & 7 & \\
\hline \multirow[t]{2}{*}{0.2} & Distilled-water & 0 & 10 & 0.01 & 0 & 10 & ns & 10 & 0 & ns \\
\hline & Experimental & 6 & 4 & & 4 & 6 & & 7 & 3 & \\
\hline \multirow[t]{2}{*}{0.1} & Distilled-water & 0 & 10 & ns & 0 & 10 & ns & 10 & 0 & ns \\
\hline & Experimental & 0 & 10 & & 0 & 10 & & 10 & 0 & \\
\hline \multirow[t]{2}{*}{0.05} & Distilled-water & 0 & 10 & ns & 0 & 10 & $\mathrm{~ns}$ & 10 & 0 & ns \\
\hline & Experimental & 0 & 10 & & 3 & 7 & & 9 & 1 & \\
\hline \multirow[t]{2}{*}{ Perch odour } & Distilled-water & 0 & 10 & ns & 0 & 10 & $\mathrm{~ns}$ & 10 & 0 & ns \\
\hline & Experimental & 0 & 10 & & 0 & 10 & & 9 & 1 & \\
\hline
\end{tabular}

Note: $P$ values are based on McNemar change tests (Siegel and Castellan 1988); ns, not significant.

Table 3. Dashing, freezing, and active-foraging behaviour in response to perch odour alone (experimental) or distilled-water control (distilled-water) trials during acquired-predator-recognition trials.

\begin{tabular}{|c|c|c|c|c|c|c|c|c|c|c|}
\hline \multirow[b]{2}{*}{ Treatment (nM) } & \multirow[b]{2}{*}{ Stimulus } & \multicolumn{3}{|c|}{ Dashing } & \multicolumn{3}{|c|}{ Freezing } & \multicolumn{3}{|c|}{ Foraging } \\
\hline & & Yes & No & $P$ & Yes & No & $P$ & Yes & No & $P$ \\
\hline 0.4 & Distilled-water & 0 & 10 & $<0.001$ & 0 & 10 & $<0.001$ & 10 & 0 & 0.003 \\
\hline \multirow[t]{2}{*}{0.2} & Distilled-water & 0 & 10 & $<0.001$ & 0 & 10 & $<0.001$ & 10 & 0 & 0.003 \\
\hline & Experimental & 9 & 1 & & 9 & 1 & & 3 & 7 & \\
\hline 0.1 & Distilled-water & 0 & 10 & $<0.001$ & 0 & 10 & 0.003 & 10 & 0 & 0.003 \\
\hline 0.05 & Experimental & 0 & 10 & & 3 & 7 & & 9 & 1 & \\
\hline \multirow[t]{2}{*}{ Perch odour } & Distilled-water & 0 & 10 & ns & 0 & 10 & ns & 10 & 0 & ns \\
\hline & Experimental & 0 & 10 & & 0 & 10 & & 9 & 1 & \\
\hline
\end{tabular}

Note: $P$ values are based on McNemar change tests (Siegel and Castellan 1988); ns, not significant.

increased dashing and freezing responses and significantly decreased foraging (Table 3). No significant change in the frequency of occurrence of dashing, freezing, or foraging was seen in minnows initially conditioned to $0.05 \mathrm{nM}$ $\mathrm{H} 3 \mathrm{NO}$ or distilled water (Table 3 ).

\section{Discussion}

These data clearly demonstrate that fathead minnows are able to detect $\mathrm{H} 3 \mathrm{NO}$ (the putative ostariophysan alarm pheromone) at concentrations far below their populationspecific minimum behavioural-response threshold. Minnows exposed to $\mathrm{H} 3 \mathrm{NO}$ at concentrations as low as $0.1 \mathrm{nM}$ paired with the odour of a novel predator were able to learn to recognize the perch cue.

Minnows appear to exhibit population-specific minimum behavioural-response thresholds to chemical alarm signals. Brown et al. (2001b) demonstrated that fathead minnows from a low-predation site fail to respond to $\mathrm{H} 3 \mathrm{NO}$ at concentrations below 0.4 nM. However, A. Mathis and R.J.F. Smith (unpub- 
lished data) found significantly lower minimum behaviouralresponse thresholds in populations exposed to high predation levels. The current data strongly suggest that the differences in these population-specific minimum behavioural-response thresholds are probably due to differential attention by individuals rather than to direct selection on receptor physiology. Individuals from populations consistently exposed to high levels of predation should be selected to respond to lower concentrations of alarm pheromones, as the cost associated with failure to respond are high. However, individuals from low predation risk populations should be selected to respond only at higher response thresholds, since the costs associated with lost foraging and (or) mating opportunities may be greater.

Hartman and Abrahams (2000) argued that fathead minnows should only respond to chemical alarm signals when the perceived risk of predation is high or when little information is available from other sensory modalities (primarily visual cues), such as in turbid waters. While this may be the case for overt (i.e., observable) responses, it is not so for covert responses. Covert responses (sensu Smith 1999) include acquired recognition of novel predators (Chivers and Smith 1994a, 1994b, 1995; Chivers et al. 1995; Brown and Godin $1999 c$ ), assessment of local predation risk (Brown and Cowan 2000; Brown and Schwarzbauer 2001; Brown et al. 2001c), life-history changes (Chivers et al. 1999), and induced morphological changes (Brönmark and Miner 1992; Stabell and Lwin 1997). Our results and those of Brown and Smith (1996) demonstrate that individual minnows are able to acquire the ability to recognize novel predators even though they do not exhibit an overt behavioural response. This strongly suggests that even though individuals may not be responding to the presence of low concentrations of conspecific alarm pheromones, they are still attending to them. In addition, it is possible that low concentrations of chemical alarm signals may actually increase vigilance towards visual predator cues (Brown and Cowan 2000; Brown and Smith 1996). This hypothesis remains to be directly tested.

\section{Acknowledgements}

The authors thank Drs. Leo Fleishman and Manuel Leal for helpful comments on previous versions of the manuscript and Mark Cornwall, SUNY Cobbleskill, for supplying the minnows. Union College and Concordia University provided financial support. The research reported here was conducted in accordance with Union College Institutional Animal Care and Use Committee protocol No. 02-27-98.

\section{References}

Brönmark, C., and Miner, J.G. 1992. Predator-induced phenotypical change in body morphology in crucian carp. Science (Washington, D.C.), 258: 1348-1350.

Brown, G.E., and Cowan, J. 2000. Foraging trade-offs and predator inspection in an ostariophysan fish: switching from chemical to visual cues. Behaviour, 137: 181-196.

Brown, G.E., and Godin, J.-G.J. 1999a. Chemical alarm signals in Trinidadian guppies: laboratory and field evidence. Can. J. Zool. 77: 562-570.
Brown, G.E., and Godin, J.-G.J. 1999b. Who dares, learns: chemical inspection behaviour and acquired predator recognition in a characin fish. Anim. Behav. 57: 475-481.

Brown, G.E., and Schwarzbauer, E.M. 2001. Chemical predator inspection and attack cone avoidance in a characin fish: the effects of predator diet. Behaviour, 138: 727-740.

Brown, G.E., and Smith, R.J.F. 1996. Foraging trade-offs in fathead minnows (Pimephales promelas, Osteichthyes, Cyprinidae): acquired predator recognition in the absence of an alarm response. Ethology, 102: 776-785.

Brown, G.E., Chivers, D.P., and Smith, R.J.F. 1997. Differential learning rates of chemical versus visual cues of a northern pike by fathead minnows in a natural habitat. Environ. Biol. Fishes, 49: 89-96.

Brown, G.E., Godin, J.-G.J., and Pedersen, J. 1999. Fin flicking behaviour: a visual antipredator alarm signal in a characin fish, Hemigrammus erythrozonus. Anim. Behav. 59: 469-476.

Brown, G.E., Adrian, J.C., Jr., Smyth, E., Leet, H., and Brennan, S. 2000. Ostariophysan alarm pheromones: laboratory and field tests of the functional significance of nitrogen-oxides. J. Chem. Ecol. 26: 139-154.

Brown, G.E., Adrian, J.C., Jr., Erickson, J.L., Kaufman, I.H., and Gershaneck, D. 2001a. Responses to nitrogen-oxides by Characiforme fishes suggest evolutionary conservation in ostariophysan alarm pheromones. In Chemical signals in vertebrates. Vol. 9. Edited by A. Marchlewska-Koj, J.J. Lepri, and D. MüllerSchwarze. Plenum Press, New York. pp. 305-312.

Brown, G.E., Adrian, J.C., Jr., and Shih, M.L. 2001b. Behavioural responses of fathead minnows to hypoxanthine-3- $\mathrm{N}$-oxide at varying concentrations. J. Fish Biol. 58: 1465-1470.

Brown, G.E., Golub, J.L., and Plata, D.L. 2001c. Attack cone avoidance during predator inspection visits by wild finescale dace (Phoxinus neogaeus): the effects of predator diet. J. Chem. Ecol. 27: 1657-1666.

Chivers, D.P., and Mirza, R.S. 2001. Predator diet cues and the assessment of predation risk by aquatic vertebrates: a review and prospectus. In Chemical signals in vertebrates. Vol. 9. Edited by A. Marchlewska-Koj, J.J. Lepri, and D. Müller-Schwarze. Plenum Press, New York. pp. 277-284.

Chivers, D.P., and Smith, R.J.F. 1994a. Fathead minnows, Pimephales promelas, acquire predator recognition when alarm substance is associated with the sight of an unfamiliar fish. Anim. Behav. 48: 597-605.

Chivers, D.P., and Smith, R.J.F. 1994b. The role of experience and chemical alarm signaling in predator recognition by fathead minnows, Pimephales promelas. J. Fish Biol. 44: 273-285.

Chivers, D.P., and Smith, R.J.F. 1995. Fathead minnows, Pimephales promelas, learn to recognize chemical stimuli from high risk habitats by the presence of alarm substance. Behav. Ecol. 6: $155-158$.

Chivers, D.P., and Smith, R.J.F. 1998. Chemical alarm signaling in aquatic predator-prey systems: a review and prospectus. Ecoscience, 5: $338-352$.

Chivers, D.P., Brown, G.E., and Smith, R.J.F. 1995. Acquired recognition of chemical stimuli from pike, Esox lucius, by brook stickleback, Culaea inconstans (Osteichthyes, Gasterosteidae). Ethology, 99: 234-242.

Chivers, D.P., Kiesecker, J.M., Marco, A., Wildy, E.L., and Blaustein, A.R. 1999. Shifts in life history as a response to predation in western toads (Bufo boreas). J. Chem. Ecol. 25: 2455-2464.

Hartman, E.J., and Abrahams, M.V. 2000. Sensory compensation and the detection of predators: the interaction between chemical and visual information. Proc. R. Soc. Lond. B Biol. Sci. 267: 571-575. 
Hazlett, B.A. 1997. The organization of behaviour in hermit crabs: response to variation in stimulus strength. Behaviour, 134: 59-70.

Lawrence, B., and Smith, R.J.F. 1989. The behavioral response of solitary fathead minnows, Pimephales promelas, to alarm substance. J. Chem. Ecol. 15: 209-219.

Magurran, A.E., Irving, P.W., and Henderson, P.A. 1996. Is there a fish alarm pheromone? A wild study and critique. Proc. R. Soc. Lond. B Biol. Sci. 263: 1551-1556.

Mathis, A., and Smith, R.J.F. 1993. Chemical alarm signals increase the survival time of fathead minnows (Pimephales promelas) during encounters with northern pike (Esox lucius). Behav. Ecol. 4: $260-265$.

Mathis, A., Chivers, D.P., and Smith, R.J.F. 1993. Population differences in responses of fathead minnows (Pimephales promelas) to visual and chemical stimuli from predators. Ethology, 93: $31-40$.

Mirza, R.S., and Chivers, D.P. 2001. Do chemical alarm signals enhance survival of aquatic vertebrates? An analysis of the current research paradigm. In Chemical signals in vertebrates. Vol. 9. Edited by A. Marchlewska-Koj, J.J. Lepri, and D. MüllerSchwarze. Plenum Press, New York. pp. 19-26.

Pfeiffer, W., Riegelbauer, G., Meier, G., and Scheibler, B. 1985. Effects of hypoxanthine-3- $N$-oxide and hypoxanthine-1- $N$-oxide on central nervous excitation of the black tetra, Gymnocorymbus ternetzi (Characidae, Ostariophysi, Pisces) indicated by dorsal light response. J. Chem. Ecol. 11: 507-523.

Siegel, S., and Castellan, N.J., Jr. 1988. Nonparametric statistics for the behavioral sciences. 2nd ed. McGraw-Hill, New York.

Smith, R.J.F. 1992. Alarm signals in fishes. Rev. Fish Biol. Fishes, 2: 33-63.

Smith, R.J.F. 1997. Does one result trump all others?: A response to Magurran, Irving and Henderson. Proc. R. Soc. Lond. B Biol. Sci. 264: 445-450.

Smith, R.J.F. 1999. What good is smelly stuff in the skin? Cross function and cross taxa effects in fish "alarm substances". In Advances in chemical signals in vertebrates. Edited by R.E. Johnston, D. Müller-Schwarze, and P.W. Sorensen. Kluwer Academic, New York. pp. 475-488.

Stabell, O.B., and Lwin, M.S. 1997. Predator-induced phenotypic changes in crucian carp are caused by chemical signals from conspecifics. Environ. Biol. Fishes, 49: 145-149.

Suboski, M.D. 1990. Releaser-induced recognition learning. Psychol. Rev. 97: 271-284.

Suboski, M.D. 1992a. Releaser-induced recognition learning by amphibians and reptiles. Anim. Learn. Behav. 20: 63-82.

Suboski, M.D. 1992b. Releaser-induced recognition learning by gastropod molluscs. Behav. Proc. 27: 1-26. 